\title{
Building Energy Analysis and Spatial Features of Museums in Historical Cities
}

\author{
Yafei Zhao", Paolo Vincenzo Genovese \\ Tianjin University, Tianjin, China
}

*Corresponding Author: Yafei Zhao, PhD, Tianjin University, Tianjin, China.

\begin{abstract}
Museum has become one of the significant cultural facilities. The background of this article is that a museum will be built near the site of the Colosseum in Rome, Italy. While seeking to establish a unified structure and function, the planning of the new museum should not undermine the original appearance of the site so as to avoid any disrespect to history. This article will start with a brief introduction to the history of museums, then summarizing the energy-analysis impacts of museums on a city, with a focus on the case studies of two representative historical cities in China, respectively Beijing and Shanghai. Through literature review, this article explores and analyzes the distribution characteristics of these urban museums and their related factors. Finally, combined with the research of mature and completed museums, several appropriate strategic suggestions will be proposed for the design and planning of the future Coliseum Museum, which provides the theoretical basis for the feasibility study.
\end{abstract}

Keywords: Museum, Historical Cities, Energy Analysis, Spatial Features, Controlling Factors

\section{INTRODUCTION}

With the development of human society, the museum has become one of the significant cultural facilities. It is a cultural heritage place for collecting and researching the objectives that represent natural and human beings, with all the items classified. Museums as well as Museology play increasingly important roles in the contemporary city. For a city, especially the historical city, the role that the museum plays is not only the inheritor of the cultural heritage but also the communicator of the entire urban culture. The concept of Culture-led Regeneration by Urry (1995) in his book Consuming Place also reflects the museum's influence on the city in which it is located ${ }^{[1]}$.

The background of this article is that a museum will be built near the site of the Colosseum in Rome, Italy. While seeking to establish a unified structure and function, the planning of the new museum should not undermine the original appearance of the site so as to avoid any disrespect to history. Therefore, it is necessary and helpful to analyze the historical cities with built museums since the initial planning for a museum is a very complex process with a variety of influencing factors. A mature design solution is not just a matter of "solving problems" in design aspect, while it is also a series of success such as municipal administration, transportation, tourism, humanities and society. This article will start with a brief introduction to the history of museums, then summarizing the impacts of museums on a city, with a focus on the case studies of two representative historical cities in China, respectively Beijing and Shanghai. Through literature review, this article explores and analyzes the distribution characteristics of these urban museums and their related factors. Finally, combined with the research of mature and completed museums, several appropriate strategic suggestions will be proposed for the design and planning of the future Coliseum Museum, which provides the theoretical basis for the feasibility study.

\section{LiTERATURE REVIEW}

Xie, et al (2014) summarized western museology and urban renewal development process, then elaborated the relationship between museum and city renewal. They described that the first contemporary museum was built in 1683 in Oxford, UK. At that moment, the museum was defined as a place to store natural and scientific objects as well as artistic works [2]. But Meng(2010) argued that the definition was only limited to two basic functions of museums, which are collection and storage[3]. Until 1974, the International Council of Museums (ICOM) gave the clear definition of contemporary museum that is more appropriate to the current society and its functions. According to 
the official introducing webpage of the development of the Museum Definition according to ICOM Statutes (2007-1946), "A museum is a non-profit making, permanent institution in the service of society and its development, and open to the public which acquires, conserves, researches, communicates and exhibits, for purposes of study, education and enjoyment, material evidence of people and their environment"[4]. Xie, et al (2014) also proposed the relationship between a museum and the city where it is located. The museum promotes the preservation of the historical and cultural heritage of the city and enhances the urban cultural image. Also, the museum promotes the economic development of the city and social acceptance [2].

With the expansion of urban population and the increasing social awareness in recent decades, the planning and construction of urban museums around the world have been triggered. This rapidly developing process has been described by scholars as 'city's museum movement' [5, 6]. According to the statistics of Museum International Journal by UNESCO, in Europe, the Museum of London tries to spend 18 million pounds on its 'capital plan' to increase $25 \%$ of the exhibition area. In North America, cities like Chicago, San Francisco, Atlanta and Boston have also proposed plans to build an urban museum. In South America, Sao Paulo is expanding its urban museum at the historic site de Santos[5]. In Asia, as a city-sized country, Singapore also announced their plan to extend the National Museum. In China, since the country has many historical cities with a large amount of population, therefore it will be more representative of this city's museum movement. In the next section, several representative Chinese cities will be selected as case studies for in-depth discussion to analyze the spatial distribution of these city museums. What these cities have in common is that they have a long history, a large population base, well-developed urban construction, reasonable planning, convenient transportation and relatively developed tourism. Therefore, the influence factors of each city museum are also multi-dimensional.

\section{CaSe STUdy ANd ANALYSiS}

\subsection{National Museum of China (Beijing, China)}

The city of Beijing is positioned as China's political center, cultural center, and economic center. At the overall planning level, Yang (2009) summarizes the three stages of time development and their distribution at each stage for all the existing museums in the city. In the early years between 1949 and 1979, it was the stage that "gathering as the center of Tiananmen Square and Forbidden City"[7]. This is because the density of buildings in Beijing's urban area was relatively low at that time, while the main functional building (mainly the Forbidden City which was used and dwelling by the royal family) became the core of Beijing. Until now, this part of the region has also served as a symbol of the history of the entire city and as a landmark. After that, from 1980 to 1995 it was the stage that had "an outward expansion along main roads and circular roads"[7]. This is because at the very beginning of China's reform and opening up (since 1975), Chang'an Avenue, which runs east and west near Tiananmen Square and the Forbidden City, developed into a main road at the time. Many government departments, functional departments, or national departments were all distributed around Chang'an Avenue. Since the 1980s, the construction of the circular ring in urban areas has caused the scale of development to expand outward from the core. From now till now, it is the stage that "along the northeast-southwest axis of agglomeration"[7]. This is because with the population increases and the transportation becomes convenient, those surrounding satellite cities were planned to be constructed, therefore the urban size of Beijing had further expansion. Northeast - Southwest is also a traditional cultural reserved area, so the distribution of museums along the line tends to these areas.

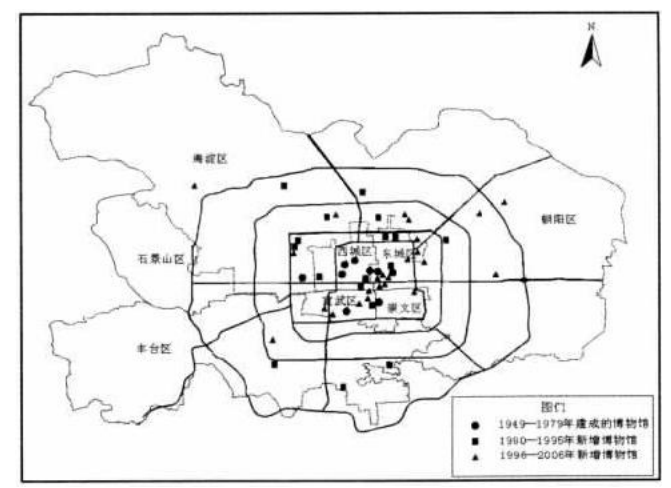

Fig1. The Present Status of Spatial Distribution of Beijing's Museums 
National Museum of China is reformed and based on the original Chinese History Museum and the Chinese Revolutionary Museum. The original building was built in 1959 and was regarded as one of the top ten famous buildings in the 1950s. When it is the 21st century, in order to repair the old museum's functions, improve the public figure's image of the national museum, the municipality decided to change its name, proposed expansion, building design and called for international bidding. The expansion project was proceeded from July 2007 to March 2011, the total construction completed with an area of nearly 200,000 square meters and a total cost of 2.5 billion yuan. Now the museum has a collection of about 1,060,000 items. National Museum of ChinaIt is located in the core area of Beijing, and on the east side of Tiananmen Square, meanwhile People's Hall, the Forbidden City, Chairman Mao Memorial Hall are located in other three directions of Tiananmen Square. Stephan Schütz, an architect at GMP Architect (Gerkan, Marg und Partner), was involved in this reforming project and explained that "our solution is to demolish the building with the fewest elements, we will keep three main facades on north, west, and south, also keep a large part of east facade. For the new built part, the modern concise could compare with the old one, which is the approach adopted by European architects, not only in the British Museum but also the reforming project for Berlin Olympic Stadium Renovation. Architects have adopted a strong contrast to deal with the relationship between old and new buildings"[8]. Schütz's point of view is mainly reflected in the use of the material and color with current characteristics, rather than "repair the new things as old".

As mentioned in the previous paragraph, the National Museum of China is made up of two old museums. How to build an organic connection becomes very important. Chinese culture is very particular about harmony and coordination. Although the purpose of reforming is not to "repair the new things as old", but it has to be sure that expansion is coordinated with the reservation. The image of new building should have a sort of connection with the old elements in order to show the evolution of the building itself in the course of history [8]. The general concept of the architectural design is to combine both ancient Chinese philosophy and contemporary architecture theory, while using Chinese traditional elements for most of the parts. This article will focus on more about planing and controlling factors for National Museum of China instead of the detailed design by architects. Consider the special position for National Museum of China, it shouldn't be single-function museum only for exhibition. Those multi-functions contain key state activities, opera shows, cultural or academic conferences. The entire reconstruction work embodies the museum's attitude toward history, not only preserving the traditional elements of China, but also embodying a wide range of development ideas.

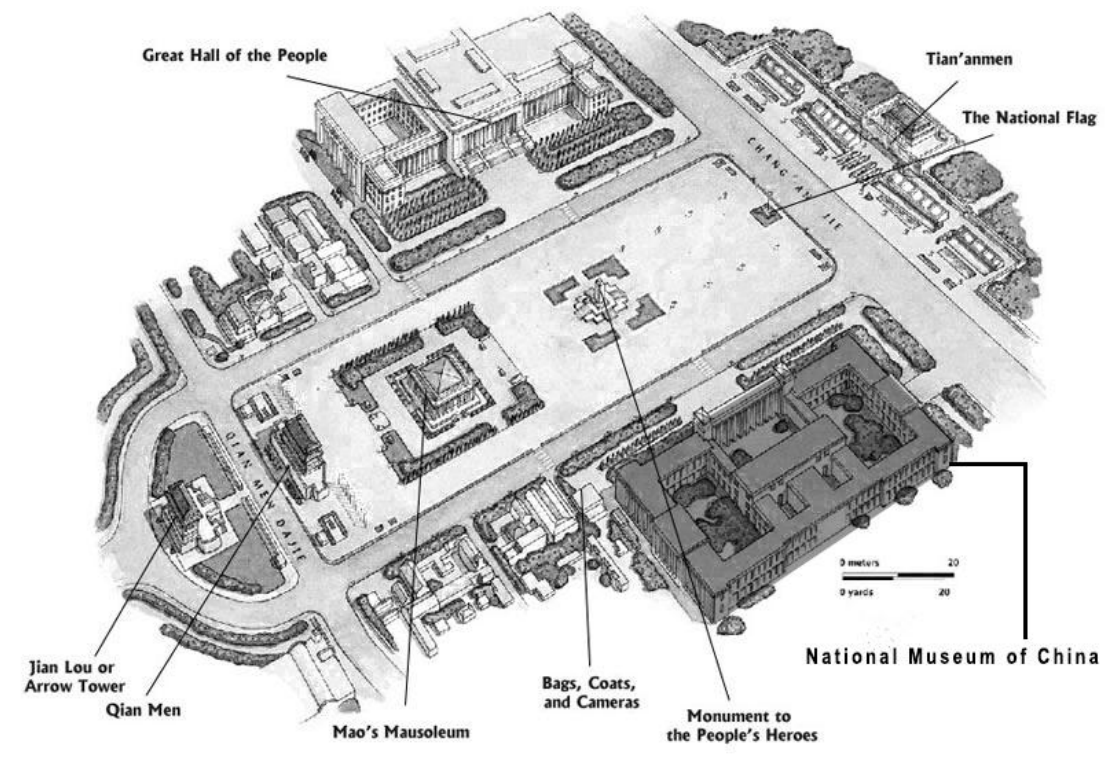

Fig2. Tian'anmen Square Layout and National Museum

For the traffic analysis, it is more likely to say that National Museum is the beneficiary rather than the promoter of urban transport planning in Beijing. Because it is located in the north-south axis, which is the so-called "Beijing Imperial Axis" from the Yong ding men to the Bell and Drum Tower, a total 
length of $7.7 \mathrm{~km}$. It is the center of the ancient capital of Beijing, and also the longest existing city axis in the world. At the same time, east and west Chang'an Avenue also formed a main traffic road. The two lines intersect in front of Tiananmen Square, together with the well-developed underground traffic lines in Beijing, have natural traffic advantages and also have huge tourism resources. The reconstruction of the National Museum has also had a profound impact on Beijing's tourism industry. In 2017, Themed Entertainment Association and AECOM together published a report called "2016 TEA/AECOM Theme and Museum Index". The report shows that among the top 20 most popular museums in the world, the National Museum of China ranks the first position with 7.55 million visitors last year [9]. In fact, three years ago, National Museum of China was only ranked in the third position. But during the past three years, its rankings soared above the U.S. NASA Museum in Washington and Louvre Museum in Paris, making it to be one of the most popular and most visited museums in the world [10]

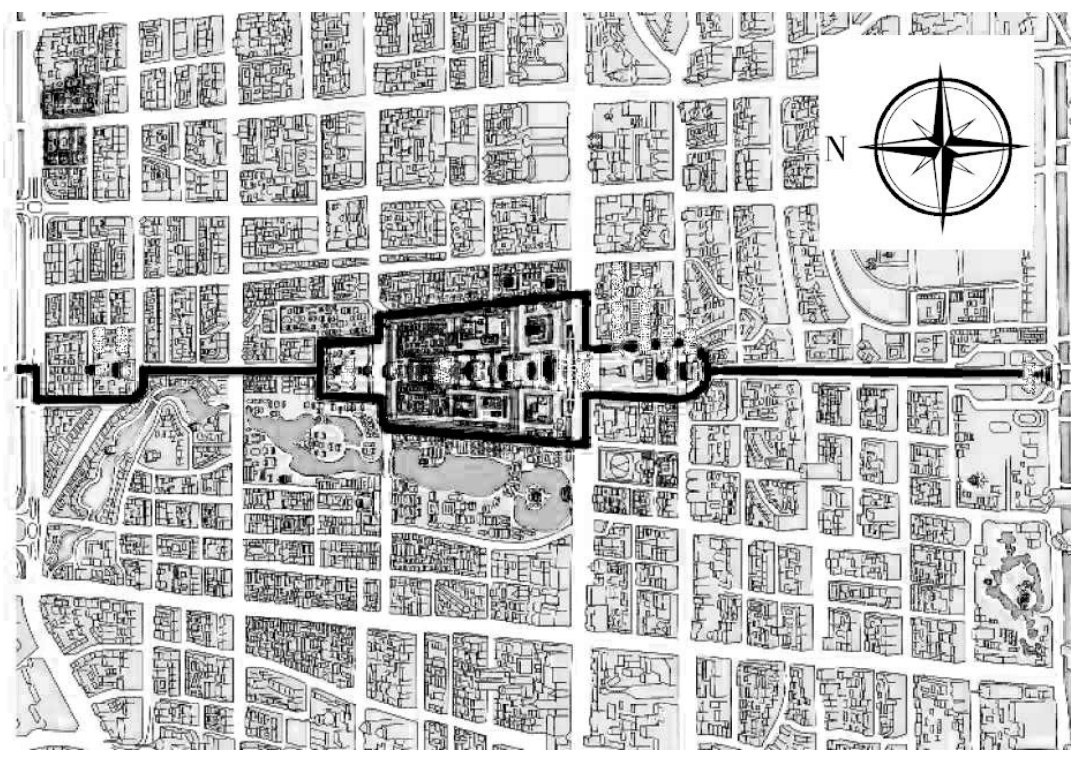

Fig3. Demonstration of Beijing Imperial Axis

\subsection{Shanghai Museum (Shanghai, China)}

Since the 1990s, the Shanghai municipal government has listed tourism as the key tertiary industry for the future development. The government proposes to enhance economic growth by improving urban tourism[11]. As one of the largest cities in the world, Shanghai has a population of more than 20 million and forms the "Yangtze River Delta City Cluster" with several cities in the nearby provinces of Jiangsu and Zhejiang. It is one of the major metropolitan areas in the world and has become a significant international transport hub in eastern China. There are many distinctive European-style buildings left during the concession period (around 1845 to 1943), and many modern buildings were built in the 1990s. At the same time, several suburban water-town towns with traditional Chinese style became tourist attractions[12]. For the overall analysis of Shanghai, firstly it must be defined as a historical city, then followed by a modern tourism city. With a few successful international events such as the World Expo 2010 held in Shanghai in recent years, its popularity has also risen, followed by the rapid development of the tourism industry. The Global Destination Cities Index (GDCI) shows that Shanghai has become the most popular city for foreign tourists in mainland China. In 2016, Shanghai received a total of 6.3 million tourists and total tourism revenue reached 5.3 billion U.S. dollars [13].

The former museum of Shanghai Museum was founded in 1952 and is mainly used for exhibitions of ancient Chinese bronzes, porcelain and sculpture. In 1996 the new Shanghai Museum opened with a total area of about 40,000 square meters, five floors and two basements. The new building is a combination of square base and round shape of the building modeling, with China's "hemispherical dome cosmology" moral. Shanghai Museum is set by north and south entrances and exits. The north side faces the People's Square, and a sunken square is designed to connect the underground lecture hall connectivity. The south side contains the main entrance with the layout of eight art sculptures to express the characteristics of architectural meaning. Shi (2002) summarized the disadvantages and major problems faced by the old Shanghai Museum before the renovation: (1) Low convenience for 
the traffic. When buses were the main transportation and the routes were too few; (2) Poor location conditions. There were too few residents or visitors around that; (3) Single-function use. Before the renovation, the main function only focused on education or research, while ignoring the improvement of leisure and tourism functions; (4) Low market attractivity. The manager was lack of market awareness without any effective publicity[11]. However, the new Shanghai Museum made an early exploratory practice in the planning and design stage. No matter from the integration of social resources, or location planning, the social function of this building has been improved in a dramatic way. In the construction phase, even the market-oriented approaches have been introduced such as social financing. Through the transfer of land ownership, a development company in Hong Kong started fundraising activities among overseas Chinese all over the world and adopted the method of naming pavilions for who funded the construction[11]. With sufficient renovation funds, the exhibition hall of the museum was built to increase the space of whole building, thus accommodating more visitors at the same time.

After reconstruction, the new Shanghai Museum was planned to locate at People's Square. People's Square is mainly composed of an open square, People's Park and some surrounding cultural, tourist and commercial buildings. It is a political, economic, cultural, tourist center and transportation hub in Shanghai. It is also one of the most important landmarks in the city[14]. There are about 30 bus stops and more than 60 bus lines in the bus hub area near the People's Square. The underground transportation includes subway line 1, line 2 and line 8. Relatively, Metro Line 1 is the earliest rail transit line built in Shanghai and one of the busiest and most important rail lines in Shanghai. Metro Line 2 connects with Nanjing Road, which is called "China's First Street", and crosses the Huangpu River and reaches Pudong New Area, finally arrives at Pudong International Airport. Metro Line 8 is one of the rail links to the site of the 2010 World Expo. Those three lines are around the East, South and North of People's Square. Within a radius of 500 meters, there are a total of three subway stations. Among them, the underground station of People's Square is the intersection of two subway lines, while it sets up more than 20 entrances and exits.There are large flow of people around the Shanghai Museum, as well as the city mansion, museums, theaters, and underground business center including several shopping malls[15], those two factors themselves are also in causal relationships.

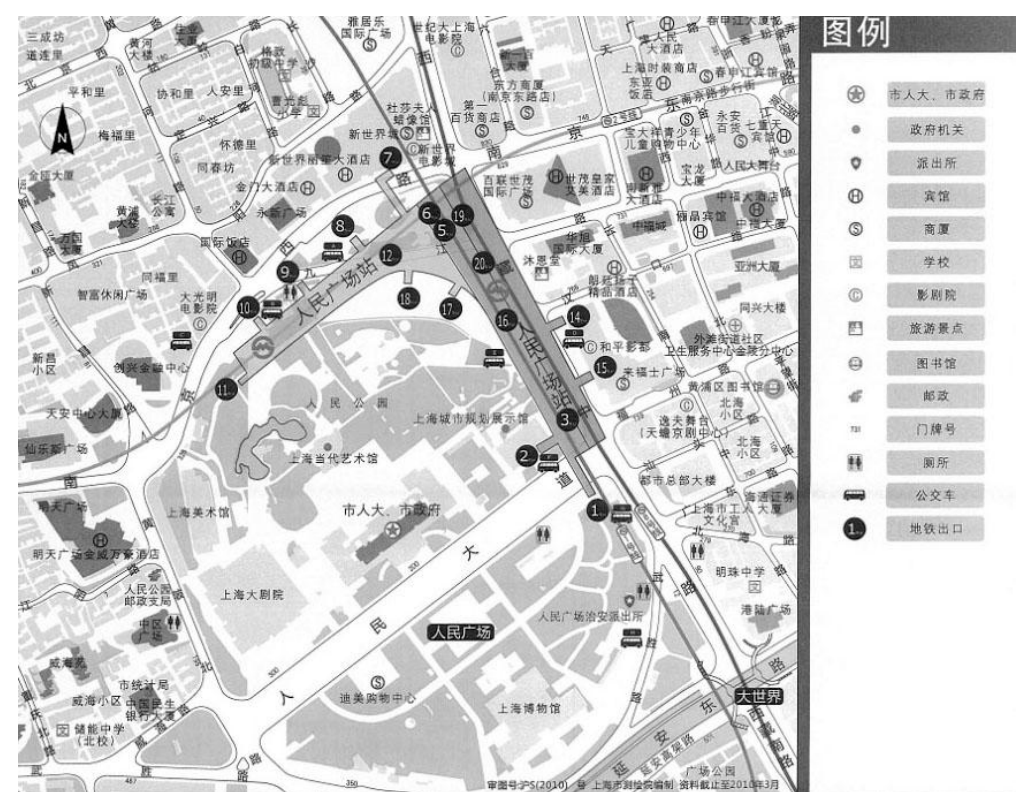

Fig4. Block Diagram and Public Transport of People's Square and Shanghai Museum

\section{DisCuSSION AND SUgGeSTIONS}

In this part, combined with the research of mature and completed museums, several appropriate strategic suggestions will be proposed for the design and planning of the future Colosseum Museum, which provides the theoretical basis for the feasibility study. It is undeniable that the Colosseum has already become one of the cultural representatives of the city of Rome. The following effective measures focus more on how to maximize the function of the future museum in the planning and design stage to play a role and undertake more responsibility in the city and society, meanwhile improving, enhancing the city's cultural taste, and popularizing historical knowledge. 


\subsection{Energy-Analysis and Historical Factors}

As a unique type of building, it's very important to research on energy saving for museums to improve its energy efficiency. At present, there are several popular software to be used for analysis, such as eQUEST, Energyplus,CHEC, PowerDOE. The recent research trend is to analyze building energy consumption by building simulation models. Building energy analysis is inseparable from data, so data sets are the core application of theory and practice. Throughout the museum's entire life cycle, a large amount of data is generated during both the design and operation phases. According to the purpose and purpose, the data set can be divided into different types. Combining the existing theoretical basis, it puts forward feasibility suggestions for the design or reconstruction of the museum.

As can be seen in some literature reviews about the city museum, the "history of the city" is not a decisive condition although it is an important factor, for example, the Shenzhen Museum in Guangdong (Canton) Province, China. Under the background of the great transformation in China, its own special influence has determined to become a new card for a young city within a short period of time. Moreover, with the demographic dividend, Shenzhen is a microcosm of the rapid economic development in China today[16]. Within only 30 years, it has grown from an uninhabited coastal fishing village to one of China's top four cities. Shenzhen Museum is the largest single-structured building in Shenzhen, located in the central axis of Shenzhen City, is a landmark for the central area[16]. The image of the building has been dubbed the wings of a fictional bird, as Shenzhen is also referred to as "the city of great bird" named. Compared with other museums with history and nature, the theme of its exhibition is special. It is based on the theme of reforming revolution in China. It mainly embodies the impact of modern urban planning and construction to the society and the inhabitants' life under the influence of modern science and technology.

In this point of discussion, the historical factor could be an extra credit for the planning of Colosseum in Rome. The magnificent history brings too much narration to visitors when they step into the future museum. Rome is the largest city with almost the largest number of population in Italy, as well as one of the largest cities in Europe. Rome is the city with the largest number of historical buildings in the world. The old city with surrounded ancient walls has witnessed more than 3,000 years of history as a symbol of European cultural heritage. In 1980, UNESCO included the ancient city of Rome, the Vatican, and the Basilica of Saint Paul into the human cultural heritage list.

\subsection{Innovative Ideas}

Shi (2002) also proposed "to change the management concept, to seek cooperation and breakthrough on tourism projects"[18]. This is the weak point of the traditional museum. Indeed, nowadays museums need to move toward rather than passive waiting to open and embrace new ideas. The modern museum should have active contact with other departments like local tourism, culture and education. The exhibition theme and operation direction need to adjust effective integration of resources according to the market demand. About the economy factor, it is well-known that a large public building needs a lot of investment to build and operate. It can be learned from the approach of Shanghai Museum that raised funds from the community or third-party investment institutions.

In addition, the cost and convenience of transportation are also important factors. Colosseum area has convenient subway and bus stations, which can relatively meet the requirements of the crowd distribution. For the small range perspective, the layout of the museum can not be affected. But if analyzing as a whole city center of Rome, lots of disadvantages of public transportation will be revealed. Due to the respects, conservation and preservation of historic buildings, many external factors have restricted the construction of underground traffic. In terms of subway transport capacity, Rome is not as convenient as other capitals of countries, such as London and Beijing. In addition, the Colosseum area is overly dependent on the single metro station and a limited number of bus stops. After field research, it is found that the Colosseum Metro station is often overloaded at times of bad weather and large-scale events, while visitors from other places are often unfamiliar with the local bus routes. This has adversely affected urban transport, which is not conducive to the distribution of tourists. An important suggestion is that the Colosseum Museum should first consider the route of escape and crowd distribution when planning the pedestrian flow. The next step is to consider visiting the navigation route in order to meet the requirements of the architectural design code. 


\section{BELONGINGNESS AND CONCLUSION}

Nowadays, urbanization has undoubtedly become the main theme in some of areas. Compared with China's cities, Rome is lack of the demographic dividend that comes from the large population base. Moreover, as the capital of a developed country, it has to accept the relocation of migrants. On the one hand, this is also a drawback that the post-urbanization brings to Rome. In the relatively fixed physical space (ie, ancient buildings), the uneven population growth brings more uncertainty to the future. In addition, Song (2014) also summarizes other factors that constrain the relationship between museums and cities. For example, the theme is single and unattractive; it has less contact with other parts of the city and has long been in a "closed" mode of development[17]. So the value of the city museum is underestimated to some extent. However, a city museum should firstly focus on the local tourist market. Local visitors can still be sub-divided into local students, local families, immigrants. After the research and investigation, there are below facts. Some museums in Rome offer free tickets for students in Academy of Arts; The Galleriedell'Accademia Venezia and Galleria degli Uffizi are free for students of European art academies. The above shows that students are important people in the local visitors and a bridge between cultural facilities and scientific research exchange. Shi (2002) used a random sampling method to adjust the source of the Shanghai Museum. The survey included socio-demographic characteristics (geographical, gender, age, educational level, occupation, income, etc.) of the tourist market as well as travel patterns, media choice and sensitivity, interest preferences and other preferences [18]. It can be seen from the conclusion that for the Shanghai Museum in China, tourists make up nearly $60 \%$ of the total population, reaching $58.64 \%$, with less than $40 \%$ of local visitors. Due to the fact that no survey has been conducted near the Colosseum in Rome, there is currently no detailed data analysis as well as the proportion of locals and tourists. Except the data "the annual number of visitors to the Colosseum, Roman Forum and Palatine Hill in Rome, Italy, from 2012 to 2016. In total around 6.4 million visits were recorded in 2016" by the research institution of Statista[19]. However, since tourism is one of the pillar industries in Rome, together with its huge international reputation, it can be inferred here that the proportion of tourists will be over $70 \%$.

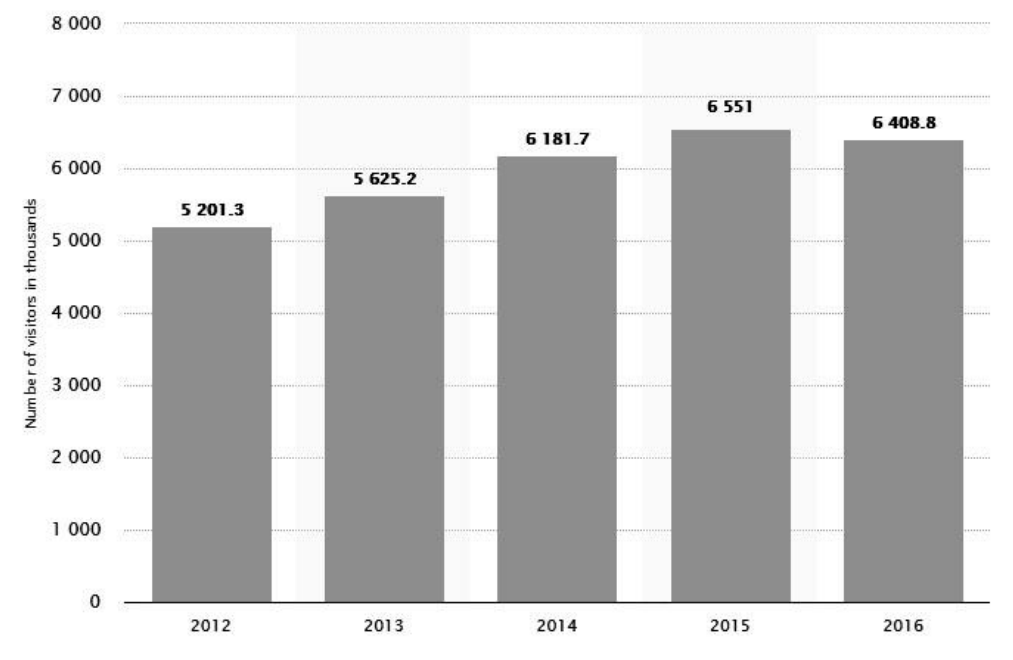

Fig5. Number of visitors to the Colosseum, Roman Forum and Palatine Hill archaeological area in Rome, Italy from 2012 to 2016

In this context, the functions of museums should be expanded beyond the traditional collection and exhibition. It is true that storing the artifacts and historical objects is the primary function of the museum, but in today's pluralistic society, museums have to bear some social significance. It is essential to enhance the museum's positioning in the community, such as upgrading to leisure, entertainment, and even positioning as a tourist destination. The belongingness should be made for not only local residents and new immigrants, but also tourists from other places instead of a hollow architectural framework. Most ancient buildings in Rome are related to religion and imperial power, which may also result in cultural or ethnic conflicts, even the psychological-unacceptable caused. On the other hand, this is precisely and the character of a city, which is exactly the meaning of an urban museum. The museum of the city also has tasks of presenting the great connotation to each participants in order to gain the sense of belongingness from the society. With the improvement of the 
current socio-economic level and the development of science and technology, people's demands for building energy saving have become higher and higher, and at the same time, the awareness of energy saving has become stronger. Low-carbon energy conservation and environmental protection have become a trend that can guarantee long-term comfortable life and development of human beings on the planet. Under the development trend of energy-saving buildings, low-energy buildings are expected to become new economic growth points. With the introduction of a series of green and lowcarbon building energy-saving technologies and products, it will drive the rapid development of the overall industry.

\section{REFERENCES}

[1] Urry, J., Consuming Places. 1995, London: Psychology Press.

[2] XieDixiang, Chu Wenhua, Museum Development Strategy under the Context of Urban Renewal. Urban Insight, 2014(4): Page 35-42.

[3] Meng Qingjin, Research on the Function Evolution of Modern Museum. Dalian University of Technology, 2010.

[4] Museums, I.C.O., Development of the Museum Definition according to ICOM Statutes (2007-1946). 2007.

[5] Zhang Wenbin, An Laishun. Urban Culture and Urban Museum. Zhuangshi, 2009(3).

[6] Tang Bin, Art Museum and Knowledge Production, 2010, China Central Academy Of Fine Arts.

[7] YANG Yun-peng, ZHANG Jing-qiu, THE ANALYSIS OF SPATIAL DISTRIBUTION FEATURES OF MUSEUMS IN BEIJING CITY. HUMAN GEOGRAPHY, 2009(05): Page 52-54.

[8] Schütz, S., Expansion Project Design For National Museum of China. Journal of Architecture, 2011(11): Page 10-12.

[9] AECOM and TEA, 2016 TEA/AECOM Theme and Museum Index. 2017. http://www.teaconnect.org/images/files/TEA_239_717418_170609.pdf

[10] National Museum of China, National Museum of China Was Named First In The World's Most Popular Museum, 2017.

[11] http://www.chnmuseum.cn/tabid/138/InfoID/113094/frtid/124/Default.aspx

[12] Shi Ping, A Research SurVey of Exploitation Of Shanghai Relic and Museum Tourist Resources -- Case Study On ShaIIghai Museum. Joumal of Guilin Institute of Tourism, 2002. 13(2): Page 68-72, 79.

[13] WikiPedia, Shanghai, 2017. https://zh.wikipedia.org/wiki/上海市

[14] MasterCard global destination cities index. MasterCard Worldwide Insights, 2017.

[15] WikiPedia, Prople’s Square, 2017. https://zh.wikipedia.org/wiki/人民广场

[16] Chen Shaoqing, Zhang Yi. Experience the City Square, Take Shanghai People's Square as an Example. Modern Science, 2008(14).

[17] Zhou Jiasheng. Construction of Museum and Urban Cultural Identity, Take Shenzhen Museum as an example. China Ancient City., 2013(5): Page 44-47.

[18] Song Haifu, Brief Discussion about the Image Orientation of City Museum in Tourism Activities. Comprehensive forum, 2014(07): Page 244, 247.

[19] Shi Ping, Research on Shanghai Museum Source Market. Journal Beijing International Studies University, 2002(04): Page 48-54.

[20] Statista, Number of visitors to the Colosseum, Roman Forum and Palatine Hill archaeological area in Rome, Italy from 2012 to 2016. 2017. https://www.statista.com/statistics/515727/rome-colosseum-androman-forum-visitor-numbers-italy

Citation: Yafei Zhao, Paolo Vincenzo Genovese, "Building Energy Analysis and Spatial Features of Museums in Historical Cities", International Journal of Constructive Research in Civil Engineering, 5(4), pp. 23-30. DOI: http://dx.doi.org/10.20431/2454-8693.0504004.

Copyright: () 2019 Authors, This is an open-access article distributed under the terms of the Creative Commons Attribution License, which permits unrestricted use, distribution, and reproduction in any medium, provided the original author and source are credited. 